\title{
In vivo testing of a bioabsorbable magnesium alloy serving as total ossicular replacement prostheses
}

\author{
Rebecca Lensing', Peter Behrens², Peter Paul Müller', Thomas Lenarz' and \\ Martin Stieve'
}

\begin{abstract}
Magnesium alloys have been investigated in different fields of medicine and represent a promising biomaterial for implants due to characteristics like bioabsorbability and osteoinduction. The objective of this study was to evaluate the usability of magnesium as implant material in middle ear surgery. Magnesium implants were placed into the right middle ear of eighteen New Zealand White rabbits. Nine animals were euthanized after four weeks and nine animals after three month. The petrous bones were removed and embedded in epoxy resin. The specimens were then polished, stained and evaluated with the aid of a light microscope. The histological examination revealed a good biocompatibility. After four weeks, a beginning corrosion of the implant's surface and low amount of trabecular bone formation in the area of the stapes base plate was observed. A considerable degradation of implants and obvious bone formation was found three month after implantation. The magnesium alloy used in the present study partly corroded too fast, so that a complete bone reconstruction could not be established in time. The increased osteoinduction on the stapes base plate resulted in a tight bone-implant bonding. Thus, a promising application of magnesium could be a coating of biomaterials in order to improve the bony integration of implants.
\end{abstract}

\section{Keywords}

Animal model, magnesium alloy, biodegradation, osteoinduction, middle ear

\section{Introduction}

Today, materials that are commonly used for total ossicular replacement prostheses (TORP) like autogenic ossicles or alloplastic materials such as $\operatorname{titan}^{1}$ are permanent implants, which are inserted to reconstruct destroyed ossicles to restore the transmission of sound from the tympanic membrane to the inner ear. These materials remain in the human body and increase the risk for infections or, in case of autogenic ossicles, promote the recurrence of the initial disease. To avoid these problems and the need for a follow-up operation for implant removal in orthopedics, bioabsorbable materials which degrade after serving their purpose were investigated. ${ }^{2,3}$ In orthopaedics, especially polymers like polyglycolic acid and polylactic acid were used as plates or screws, but showed adverse effects like local tissue reactions. ${ }^{4}$ The same polymers were examined as cardiovascular devices such as coronary stents, but revealed excessive neointima proliferation with complete occlusion of vessels and inflammatory reactions. ${ }^{5}$

Another material which is bioabsorbable and which becomes more and more important in implant research is magnesium. This metal degrades in a corrosion process whereas magnesium ions are released and then removed through phagocytosis. ${ }^{6}$ As a natural component of the human body, magnesium provides a good biocompatibility. ${ }^{7,8}$ It possesses no allergic potential ${ }^{9}$ and causes no distinct inflammatory reactions, which

\footnotetext{
'Department of Otolaryngology, Hannover Medical School, Hannover, Germany

${ }^{2}$ Institute for Inorganic Chemistry, Leibniz University of Hannover, Hannover, Germany

${ }^{3}$ Helmholtz Center for Infection Research, Braunschweig, Germany
}

Corresponding author:

Rebecca Lensing, Department of Otolaryngology, Hannover Medical School, Carl-Neubergstraße I, 30625 Hannover, Germany.

Email: Lensing.Rebecca@mh-hannover.de 
is demonstrated by many animal experiments. ${ }^{8,10-12}$ Compared to other biodegradable materials like polymers, magnesium shows higher mechanical strength and fracture toughness. ${ }^{7,13}$ Furthermore, it is reported that magnesium has an osteoinductive ${ }^{12}$ and osteoconductive effect. ${ }^{8,12-14}$ While osteoblasts are stimulated and new bone develops, the implant disappears gradually and a follow-up surgery to remove the implant is not necessary. This decreases costs, anesthetic risks and adverse psychological effects on the patients. ${ }^{2,3}$ In orthopedics, screws or plates made of magnesium alloys have been investigated ${ }^{13}$ as well as magnesium scaffolds for cartilage repair that promote peri-implant bone remodelling. ${ }^{6}$ Positive results have not only been presented in orthopedics but especially in cardiac surgery, where magnesium is used as basic material for the manufacture of intravascular stents. Implantation in humans showed absorption of magnesium stents and replacement by tissue without excess restenosis., 5,7 Even children have been provided with magnesium stents, which presents a special challenge because of further growth and therefore risk of restenosis. For example, Zartner et al. $^{15}$ described the successful implantation of a biodegradable magnesium stent into the left pulmonary artery of a preterm baby because of a previous inadvertent ligation of this artery. In this study, we wanted to investigate whether magnesium could serve as a material in middle ear surgery as well. With focus on ossification, we examined histologically the replacement of magnesium implants with endogenous bone to build up a new ossicular chain in the rabbit's middle ear.

\section{Materials and methods}

The TORPs consisted of magnesium alloy ZEK 100, produced by the Institute of Materials Science, Leibniz University Hannover. This alloy is composed of $98.4 \mathrm{wt} \%$ magnesium, $1.4 \mathrm{wt} \%$ zinc, $0.1 \mathrm{wt} \%$ zirconium, $0.1 \mathrm{wt} \%$ rare earth elements (cerium/lanthan/ neodymium/praseodym) and offers an initial tensile strength. ${ }^{16}$ The cylindrical implants (Figure 1) were manufactured with a length of $2 \mathrm{~mm}$ and a diameter of $1 \mathrm{~mm}$ and were sterilized with plasma sterilization before implantation.

For the animal experiment (Ref: 33.9-42502-04-09/ 1735, administrative district council of Hannover), 18 female New Zealand White rabbits, weighting from 3 to $3.3 \mathrm{~kg}$, were obtained from the laboratory animal breeding farm Charles River in Sulzfeld, Germany. The rabbits were kept adequately in the Institute for Laboratory Animal Science and Central Animal Facility of Hannover Medical School, Germany.

The sedation of the rabbits was performed with an intramuscular injection of ketamin (Ketamin Gräub ${ }^{\circledR}$,
$25 \mathrm{mg} / \mathrm{kg}$, Albrecht, Aulendorf, Germany) and midazolam (Midazolam-ratiopharm ${ }^{\circledR}, 1.25 \mathrm{mg} / \mathrm{kg}$, ratiopharm, Ulm, Germany). The animals got carprofen (Rimadyl ${ }^{\circledR}$, $4 \mathrm{mg} / \mathrm{kg}$ s.c., Pfizer, Berlin, Germany) and buprenorphin $\left(\right.$ Temgesic $^{\circledR}, 0.05 \mathrm{mg} / \mathrm{kg}$ s.c., Essex Pharma, München, Germany) for pain treatment and glycopyrroniumbromid (Robinul ${ }^{\circledR}, 0.1 \mathrm{mg} / \mathrm{kg}$ s.c., Riemser, Germany) to reduce side effects of the anaesthetics. The eyes of the rabbits were protected with ophthalmic ointment (Bepanthen ${ }^{\circledR}$ Augen- und Nasensalbe, Bayer, Leverkusen, Germany). Propofol (Propofol-Lipuro $1 \%{ }^{\circledR}, 2 \mathrm{mg} / \mathrm{kg}$ i.v., B. Braun, Melsungen, Germany) was given intravenously through the auricular vein to enable the intubation. During surgery, inhalation of isofluran (Isofluran ${ }^{\circledR}$, Baxter, Unterschleißheim, Germany) continued anaesthesia and electrolyte solution (Sterofundin-HEG- $5^{\circledR}, 10 \mathrm{~mL} / \mathrm{kg} / \mathrm{h}$, B. Braun, Melsungen, Germany) stabilized the rabbits' circulation. After shaving the operating area closely, the disinfection was done with povidon jodine $\left(\right.$ Braunol $^{\circledR}$, B. Braun, Melsungen, Germany).

The prostheses were implanted into the right middle ear of the rabbits. A laser microscope (OPMI Twin ER, Carl Zeiss AG, Oberkochen, Germany) was used during surgery. The external acoustic meatus was exposed through a retroauricular incision of the skin and the division of the muscles. The meatus was opened and after dissection of a tympanomeatal flap, the posterior wall of the external auditory canal was removed to get access to the tympanic cavity. After removing the ossicles, the prostheses were positioned between the tympanic membrane and the stapes base plate without special fixation. Then the tympanomeatal flap was replaced and a tamponade $\left(\right.$ Gelita $^{\circledR}$, B. Braun, Melsungen, Germany) was used to close the external

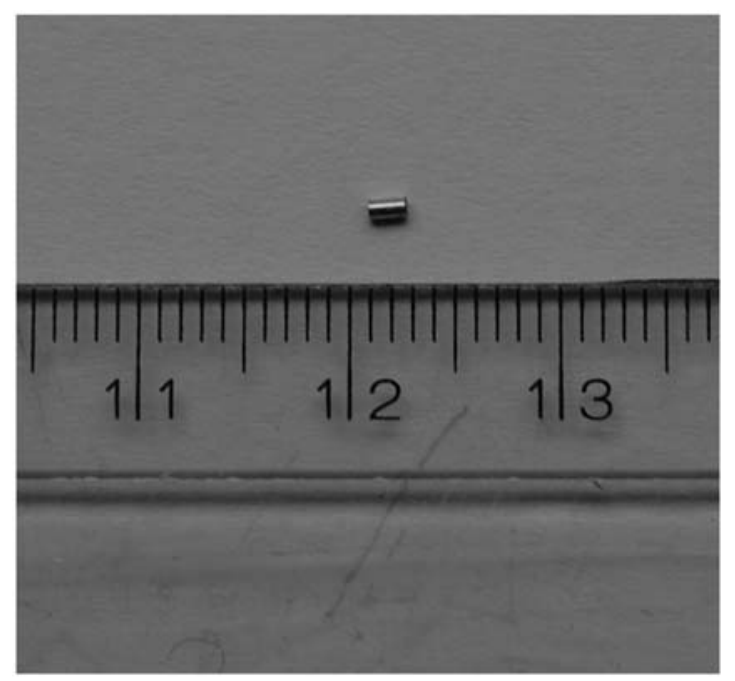

Figure I. Cylindrical magnesium alloy implant. 
auditory canal. Non-absorbable surgical suture material (Supolene ${ }^{\circledR}$, RESORBA Wundversorgung, Nürnberg, Germany) was used to close the wound rims.

The rabbits were examined twice a day, whereas their clinical general condition and the wound area were documented. To avoid inflammatory response and pain, the animals got carprofen (Rimadyl ${ }^{\circledR}, 4 \mathrm{mg} /$ kg s.c., Pfizer, Berlin, Germany) for 2 days. Additionally, enrofloxacin (Baytril ${ }^{\circledR}, 5 \mathrm{mg} / \mathrm{kg}$ s.c., Bayer, Leverkusen, Germany) was given as antibiotic prophylaxis for 10 days. In case of neurological disorders as a result of auditory nerve irritation, we administered vitamin B1 (Betabion ${ }^{\circledR} 100 \mathrm{mg}, 10 \mathrm{mg} / \mathrm{kg}$ p.o., Merck Serono, Darmstadt, Germany) and vitamin B6 (Vitamin B6-Hevert ${ }^{\circledR}$ Tabletten, $5 \mathrm{mg} / \mathrm{kg}$ p.o., Hevert-Arzneimittel, Nussbaum, Germany) to support neurological function as well as prednisolone (SoluDecortin $^{\circledR}, 1 \mathrm{mg} / \mathrm{kg}$ s.c., Merck Pharma, Darmstadt, Germany) to treat swelling.

The rabbits were assigned to two groups, whereas one group (group 1, $n=9$ ) was euthanized after 4 weeks and the other group (group 2,n=9) after 3 months. After sedation with ketamin (Ketamin Gräub $^{\circledR}, \quad 25 \mathrm{mg} / \mathrm{kg}$ i.m., Albrecht, Aulendorf, Germany) and midazolam (Midazolam-ratiopharm ${ }^{\circledR}$, $1.25 \mathrm{mg} / \mathrm{kg}$ i.m., ratiopharm, Ulm, Germany), the rabbits received propofol intravenously (Propofol-Lipuro $1 \%{ }^{\circledR}, 2 \mathrm{mg} / \mathrm{kg}$ i.v., B. Braun, Melsungen, Germany) and were then euthanized with pentobarbital (Release ${ }^{\circledR}, 600 \mathrm{mg} / \mathrm{kg}$ i.v., WDT, Garbsen, Germany). Immediately after determining the death, the middle ears were fixed with paraformaldehyde $(4 \%)$ through the tympanic membrane. The petrous bones were removed and stored in $4 \%$ paraformaldehyde before dehydrating the specimens with increasing concentrations of ethanol. The petrous bones were dried by $65^{\circ} \mathrm{C}$ for $24 \mathrm{~h}$ and then embedded in epoxy resin (SpeciFix $20 \mathrm{Kit}^{\circledR}$, Struers A/S, Rodovre, Denmark) under vacuum conditions. The specimens were ground and polished using a grinding machine (LaboPol- $5^{\circledR}$, Struers A/S, Rodovre, Denmark) and stained with a modified staining by Mann-Dominici, consisting of $0.5 \%$ Toluidine blue (Sigma, St. Louis, USA), 0.1\% Eosine G (Merck, Darmstadt, Germany) and 0.25\% Orange G (Merck, Darmstadt, Germany). The histological examination was done with the aid of a light microscope (VHX-600, 20-200 × magnification, Keyence Corporation, Osaka, Japan) with integrated imaging software for recording every grinding plane.

Degradation of the implants and ossification were evaluated on the basis of a scoring system (Table 1) and are expressed as the mean of each group.

\section{Results}

The postoperative period passed off without complications except for two animals suffering from nystagmus and slight head tilt due to an irritation of the auditory nerve during surgery. Four other rabbits showed mild inflammatory reactions of the wound area for about 3 days. Overall, we did not observe any impairment of the rabbits' general condition or severe inflammation with delayed wound healing.

The macroscopic examination of the right outer ear after euthanasia revealed a smaller lumen of the external auditory canal than the auditory canal of the left ear. In the histological examination, the mucosa of the external auditory canal was not thickened and no inflammatory reactions were observed (Figure 2(a) to (c)). In the lumen of the auditory canal, little amount of detritus and residues of the tamponade were found. The tympanic membrane was injured when fixation of the middle ear was performed (Figure 2(b)), but apart from that no alterations were determined.

Three implants were dislocated after 4 weeks, the other six implants of group 1 were found in the area of the stapes base plate. In group 2, the correct position of the implants in three specimens was evaluated by

Table I. Evaluation of the histological findings. Degradation and ossification of the magnesium alloy implants.

\begin{tabular}{ll}
\hline Score & Degradation \\
\hline 0 & No degradation \\
\hline & Minor degradation (beginning degradation on the surface of the implant) \\
2 & Substantial degradation (loss of structure of the implant because of degradation) \\
3 & Complete degradation \\
Score & Ossification \\
\hline 0 & No bone formation \\
\hline & Little bone formation (few bone trabeculae) \\
2 & Increased bone formation (obvious trabecular bone structure) \\
\hline
\end{tabular}



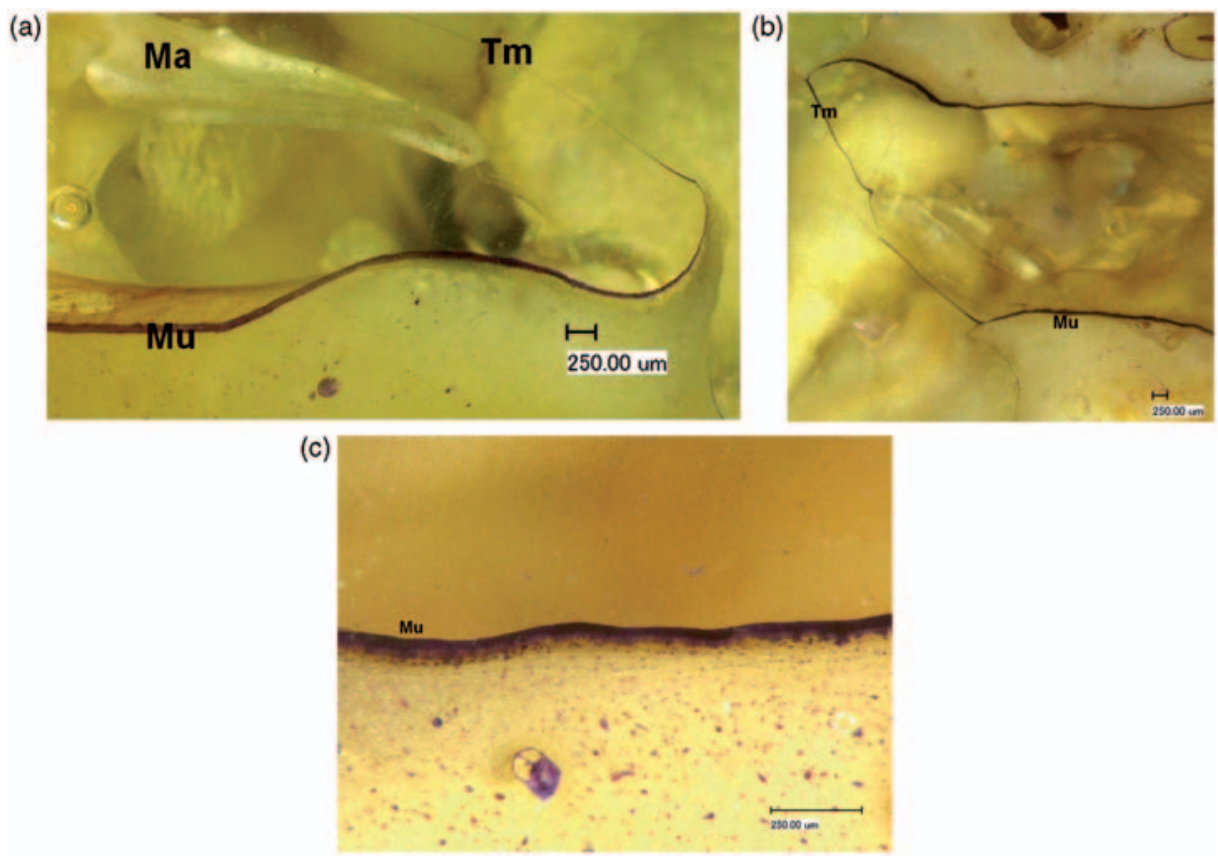

Figure 2. Mucosal coverage of the external auditory canal: (a) specimen of a physiological left middle ear with the intact tympanic membrane and malleus; (b) specimen after 4 weeks of implantation showing a regular mucosa and the injured tympanic membrane due to the preparation process; (c) higher magnification of the unaffected mucosa; Mu = Mucosa, Tm $=$ Tympanic membrane, $\mathrm{Ma}=$ Malleus.

newly formed tissue in the area of the stapes base plate because of the advanced degradation of the magnesium. One of these specimens revealed no ossification, so that the implant might be dislocated. Another specimen of this group revealed a dislocated implant, but also newly formed bone tissue on the stapes base plate, so that this implant could be dislocated during preparation. All other implants in this group were not dislocated. The specimens with dislocated implants have also been included in the evaluation, because of the assumption that degradation process and ossification of dislocated and not dislocated implants were similar.

As expected, no signs of inflammation were observed in the surrounding tissue of the implant. The mucosa of the middle ear was not thickened and appeared regular in all specimens. In case of less degraded implants, a mucosal coverage could be observed $(72 \%, n=9)$. Furthermore, the surrounding tissue revealed no signs of disorders due to gas production as a result of the degradation process.

The histological examination showed a beginning corrosion of the implant's surface after 4 weeks and an increased degradation of all implants after 3 months (Table 2, Figure 3).

Production of new bone was found especially in the area of the stapes base plate, where the implants had been placed in direct contact to bone tissue. Additionally, newly formed bone was observed, when $\mathrm{Mg}$ was in contact to remaining ossicles. The new tissue
Table 2. Degradation of magnesium alloy implants after 4 weeks (a) and 3 months (b).

\begin{tabular}{ll}
$\begin{array}{l}\text { Degradation } \\
\text { score }\end{array}$ & $\begin{array}{l}\text { Percentage of } \\
\text { specimens, } n=9\end{array}$ \\
\hline (a) after 4 weeks & \\
0 & 0 \\
I & 33.3 \\
2 & 55.6 \\
3 & 11.1 \\
(b) after 3 months & \\
0 & 0 \\
I & 0 \\
2 & 66.7 \\
3 & 33.3 \\
\hline
\end{tabular}

appeared as trabecular bone structure and always contacted the implant surface. After 4 weeks (Figure 4), increased bone formation was found in $22.2 \%(n=9)$ (score 2), while $44.4 \%(n=9)$ showed already little bone like matrix formation. The specimens, which were harvested after 3 months (Figure 5), presented increased bone formation in $55.6 \%(n=9)$ (score 2) whereas $33.3 \%$ of the nine samples showed little bone formation and where allocated to score 1. Table 3 

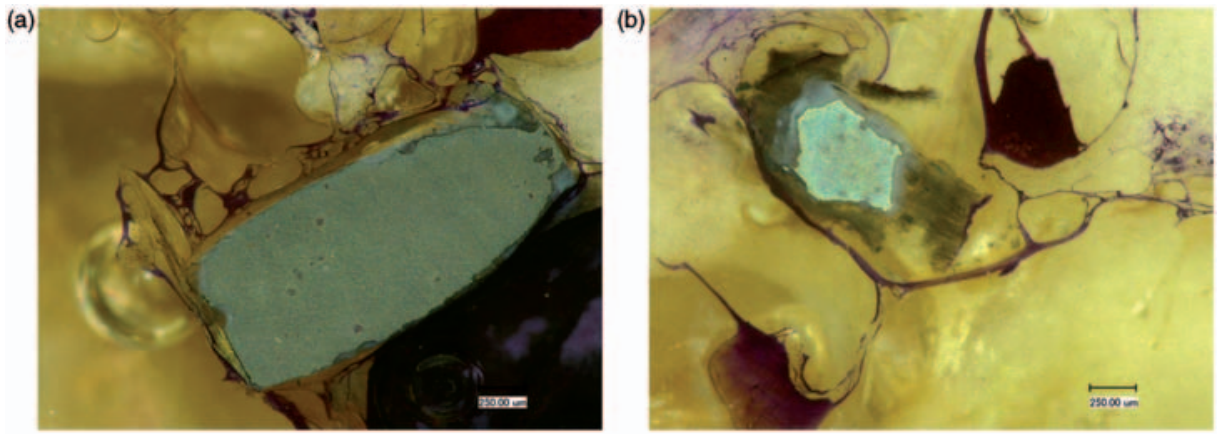

Figure 3. Specimens after 4 weeks of implantation with different degradation scores: (a) degradation score I; (b) degradation score 2.

(a) Beginning corrosion on the surface of a magnesium alloy implant, the structure of the cylindrical prostheses is still recognizable.

(b) Substantial degradation of a magnesium alloy implant, the ends of the prostheses have almost been degraded completely.

(a)

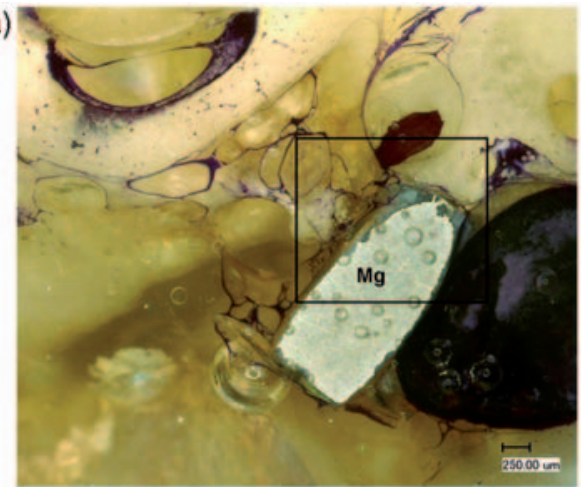

(c)

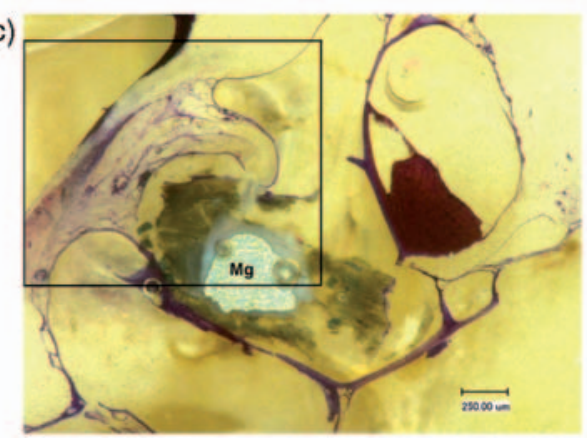

(b)

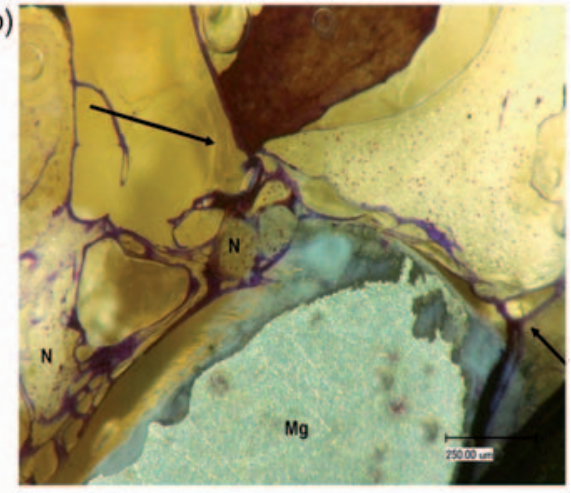

(d)

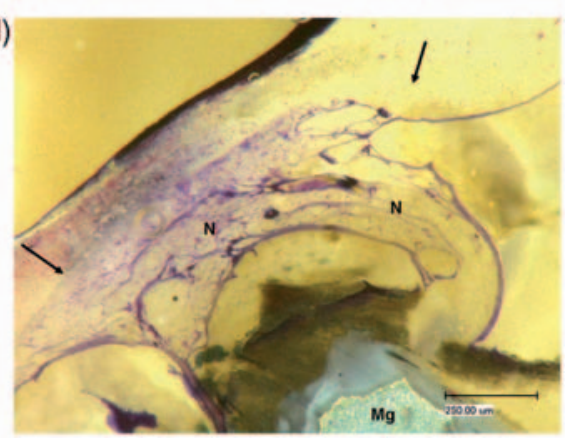

Figure 4. Ossification after 4 weeks of implantation. Overview of a specimen with little bone formation (a) and a specimen with increased bone formation (c); higher magnification (b: marked area of a, d: marked area of c) showing the new bone formation in the area of the stapes base plate (between the black arrows). $\mathrm{Mg}=$ Magnesium alloy implant, $\mathrm{N}=\mathrm{New}$ bone formation.

shows the correlation between degradation rate and new bone formation.

\section{Discussion}

The purpose of this study was to examine the applicability of magnesium as basic material for ossicular replacement prostheses. In a rabbit model, the ossicles were replaced by cylindrical implants consisting of the magnesium alloy ZEK 100 which was chosen because of its high content of magnesium. As there are to our knowledge no other studies dealing with the behaviour of magnesium in the middle ear, we initially wanted to investigate the characteristics of almost pure magnesium in this location. The implants were positioned on the stapes footplate to induce ossification and thus building up a new ossicular chain similar to a columella consisting of endogenous bone.

Magnesium corrodes in aqueous media releasing magnesium ions. After implantation, these ions are 
(a)

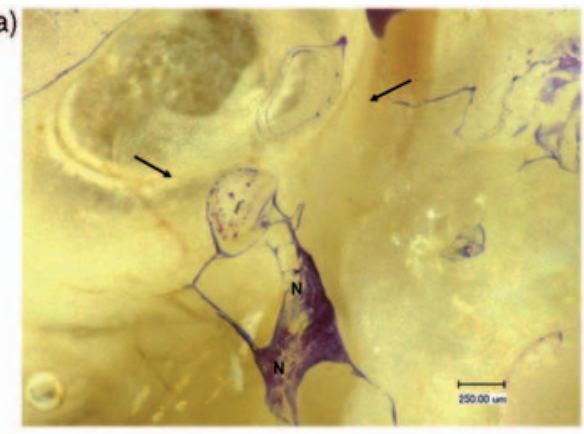

(c)

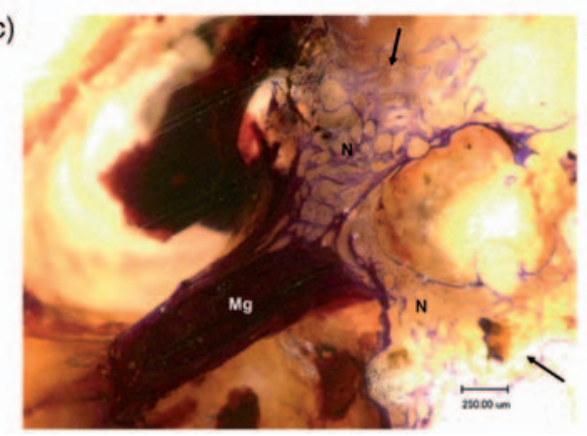

(b)

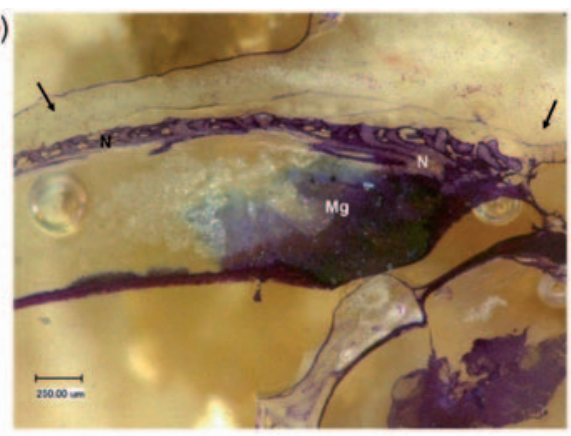

(d)

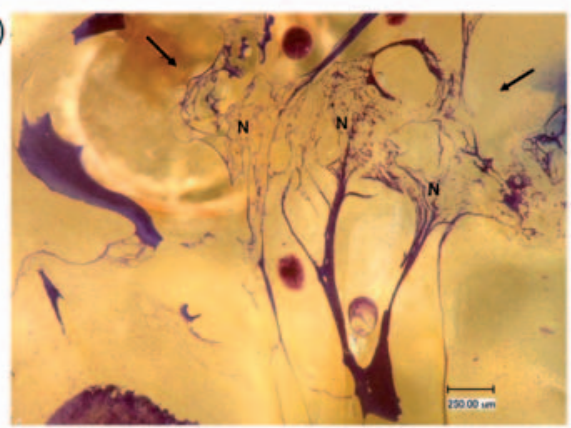

Figure 5. Ossification after 3 months of implantation. Specimen with little bone formation (a) (score I); Specimen with increased bone formation (b, c, d) (score 2). Black arrows mark the area of the stapes base plate, $\mathrm{N}=\mathrm{New}$ bone formation, $\mathrm{Mg}=\mathrm{Residual}$ magnesium alloy implant.

Table 3. Comparison of degradation and ossification after 4 weeks (a) and 3 months (b).

\begin{tabular}{lll}
\hline Specimen & $\begin{array}{l}\text { New bone } \\
\text { formation } \\
(\text { score } 0-2)\end{array}$ & $\begin{array}{l}\text { Degradation } \\
\text { (score 0-3) }\end{array}$ \\
\hline (a) after 4 weeks & & \\
I & 2 & 1 \\
2 & 0 & 2 \\
3 & 1 & 1 \\
4 & 1 & 2 \\
5 & 2 & 2 \\
6 & 0 & 3 \\
7 & 1 & 1 \\
8 & 1 & 2 \\
9 & 0 & 2 \\
(b) after 3 months & & 2 \\
1 & 2 & 3 \\
2 & 0 & 3 \\
3 & 1 & 2 \\
4 & 2 & 2 \\
5 & 2 & 2 \\
6 & 1 & 2 \\
7 & 2 & 2 \\
8 & 1 & 2 \\
9 & & 2 \\
\hline
\end{tabular}

absorbed by the body and excreted or utilized in the body's metabolism. The physiological magnesium ion concentration is regulated by the kidneys and intestine. ${ }^{13}$ A beneficial characteristic of magnesium as implant material is the osteoinduction (stimulation of new bone formation) capacity. As a result, endogenous bone replaces the degraded implant and a second surgery for implant removal is not necessary. ${ }^{8,12,13}$ Furthermore, the foreign body has disappeared and the risk for infection is thereby reduced. ${ }^{2}$

In this study, degradation of magnesium alloy implants and new bone formation was demonstrated in a living organism. The two study groups revealed different degradation stages in correlation with varying extents of ossification. A well-known problem of many magnesium alloys investigated is the high corrosion rate depending on the environment. ${ }^{11,12}$ It has been documented, that there are obvious differences in degradation rates of magnesium alloy implants at various sites of the body. ${ }^{11}$ Especially chloride containing aqueous media like the physiological body fluid leads to a fast degradation of magnesium, ${ }^{7,13}$ whereas in atmosphere a natural oxide film on the surface protects magnesium from corrosion. ${ }^{17-19}$ Therefore we assumed that in middle ear surgery with an air-filled location, the degradation may be reduced and osteoinduction could be performed. After 4 weeks, the specimens showed different progress of corrosion ranging from minor to 
complete degradation. A possible explanation for this variability could be differences in the amount of wound secretion during and after surgery. In group 1 for example, an increased bleeding occurred during surgery in one rabbit. In the histological examination this specimen showed no ossification and a complete degradation.

Another disadvantage of magnesium described in literature is the production of gas during the corrosion process. ${ }^{13,20}$ In a study of Witte et al., ${ }^{20}$ gas was observed clinically as subcutaneous gas bubbles around the guinea pig femora and was also documented by radiography. Similar results were noticed in a rabbit model, which demonstrated also the correlation between the degradation rate and the generation of gas. $^{21}$

In this study, obvious gas production was neither found in the clinical examination nor in the histological specimens. A possible reason could be again the airfilled location in contrast to body fluid containing sites like the femur or other positions mentioned in the studies before. Thus in the middle ear, magnesium ions come into contact with body fluid to a lesser extent so that gas production is inhibited. Furthermore, gas is resorbed by the organism up to a certain point, ${ }^{22}$ so that the organism can manage a little amount of gas this way. Greater quantities of gas and the following increased pressure in the middle ear could also be compensated by the Eustachian tube, so that this consequence of magnesium corrosion may be irrelevant at this location.

In contrast to other researchers, ${ }^{21}$ we noticed a correlation between new bone formation and the degradation rate. The more advanced the implant degradation, the smaller was the bone tissue formation (Table 3). After 4 weeks, most of the specimens showed already increased corrosion, but also few bone like matrix formation. Two implants of this group revealed beginning corrosion. In consequence, obvious ossification was found in the area of the stapes base plate. In three cases no bone formation could be detected. The specimens without new bone showed in one case a highly degraded implant and in the other two cases dislocated implants. This result demonstrates the importance of the contact between the implant and bone, because magnesium induces differentiation and growth of stromal cells towards an osteoblast-like phenotype ${ }^{23,24}$ implying a direct connection of the metal with tissue cells. After 3 months, most of the specimens showed increased degradation of the implants, but also obvious bone formation. Three implants were completely degraded. Two of them induced only a minor ossification on the stapes base plate. This suggests the right position of the implants, but a degradation process too fast to initiate more newly formed bone tissue. In the other specimen no new bone formation was found, so that this implant might be dislocated and osteoinduction failed.

Although osteoinduction was proved, it has to be point out that the magnesium alloy tested in the present study seems not to be appropriate as basic material for ossicular replacement prostheses. Even in an air-filled location like the middle ear, the corrosion rate of this magnesium alloy is too fast and a proliferation of bone tissue in the form of a columella was not found, so that a connection to the tympanic membrane could not be established.

There are many studies dealing with the influence of alloying elements, manufacture processing, heat treatment and other options to slow down the corrosion rate $^{7,13,20}$ A possible way to enable the application of bioabsorbable magnesium for total ossicular replacement prostheses could be the development of magnesium alloys with reduced degradation rates to improve new bone tissue formation.

Furthermore an opportunity to provide a better osteoconductive structure for new bone formation could be the use of porous magnesium implants. There are many studies which demonstrate the enhanced osteogenesis of porous versus solid implants. ${ }^{25}$ This is due to the property of pores to allow migration and proliferation of osteoblasts and mesenchymal cells, as well as vascularization, ${ }^{26}$ resulting in a better nutritional situation. When using porous materials, the appropriate choice of pore size is important, because pore volume and size affect the mechanical properties. ${ }^{13,25}$ Additionally, the degradation rate is necessary, because materials with high degradation rates should not have high porosity since rapid depletion of the biomaterial will compromise the mechanical integrity. ${ }^{14,25}$

Another promising application of the metal magnesium in middle ear surgery could be a magnesium coating for the purpose of a tighter connection between implant and stapes base plate. The bone-implant bonding is very important to prevent implant extrusion and therefore to ensure a correct sound transmission. ${ }^{1,27}$ In previous studies the positive effect of surface modification of different materials with magnesium ions was demonstrated. ${ }^{27-29}$ Zreiqat et al. ${ }^{27}$ showed an increase in osteoblast adhesion to alumina modified with magnesium and showed also the characteristic of magnesium to enhance the differentiation of cells, which is the deciding step for a tighter bone-implant bonding. ${ }^{25}$ In a study performed by Revell et al., ${ }^{28}$ an increased interfacial strength of hydroxyapatite implants enriched with magnesium was found. Similar positive effects of magnesium coated materials are shown in a study of Yamasaki et al. ${ }^{29}$ In middle ear surgery, a partial magnesium coating on the site which will be in contact to 
the stapes base plate could be helpful to strengthen the bone-implant bonding.

In conclusion, the present animal model confirms the good biocompatibility and osteoconduction of magnesium. A possible application in middle ear surgery could be a modification of common materials with magnesium ions to improve integration of middle ear implants, especially in the area of the stapes base plate.

\section{Conclusion}

The present animal study proves the degradation and the biocompatibility of magnesium alloy ZEK 100 in the rabbit's middle ear, while new bone tissue was formed especially in the area of the stapes base plate. The magnesium alloy used in the present study partly corroded too fast, so that a complete bone reproduction in form of a columella could not be established. Further research concerning the degradation rate is needed to enable the application of magnesium as basic material in middle ear surgery. Regarding the new bone formation at the stapes base plate, our findings demonstrates the increased osteoconduction on this position resulting in a tight bone-implant bonding. Therefore a possible application of magnesium could also be a coating of middle ear prostheses in order to improve the integration of the implants.

\section{Acknowledgement}

The authors would like to thank Dr.-Ing. Dirk Bormann from the Institute of Materials Science, Leibniz University Hannover for providing the magnesium implants and also Peter Erfurt for his technical support concerning the histological preparations.

\section{References}

1. Lüers JC, Beutner D and Hüttenbrink KB. Reconstruction of the ossicular chain current strategies. Laryngorhinootologie 2010; 89(3): 172-184.

2. Ashammakhi N, Suuronen R, Tiainen J, et al. Spotlight on naturally absorbable osteofixation devices. J Craniofac Surg 2003; 14(2): 247-259.

3. Witte F, Podolsky C, Hassel T, et al. Fertigung von Magnesium-Implantaten. wt Werkstattstechnik. Düsseldorf: Springer-VDI-Verlag, 2004, pp. 692-696.

4. Kontakis GM, Pagkalos JE, Tosounidis TI, et al. Bioabsorbable materials in orthopaedics. Acta Orthop Belg 2007; 73(2): 159-169.

5. Erbel R, Böse D, Haude M, et al. Absorbable coronary stents New promising technology? Herz 2007; 32(4): 308-319.

6. Witte F, Ulrich $\mathrm{H}$, Palm $\mathrm{C}$, et al. Biodegradable magnesium scaffolds: Part II: peri-implant bone remodeling. J Biomed Mater Res A 2007; 81(3): 757-765.
7. Zeng R, Dietzel W, Witte F, et al. Progress and challenge for magnesium alloys as biomaterials. Adv Eng Mater 2008; 10(8).

8. Witte F, Ulrich H, Rudert M, et al. Biodegradable magnesium scaffolds: Part 1: appropriate inflammatory response. J Biomed Mater Res A 2007; 81(3): 748-756.

9. Witte F, Abeln I, Switzer E, et al. Evaluation of the skin sensitizing potential of biodegradable magnesium alloys. J Biomed Mater Res A 2008; 86(4): 1041-1047.

10. Waksman R, Pakala R, Kuchulakanti PK, et al. Safety and efficacy of bioabsorbable magnesium alloy stents in porcine coronary arteries. Catheter Cardiovasc Interven 2006; 68(4): 607-617.

11. Heublein B, Rohde R, Kaese V, et al. Biocorrosion of magnesium alloys: a new principle in cardiovascular implant technology? Heart 2003; 89(6): 651-656.

12. Xu L, Yu G, Zhang E, et al. In vivo corrosion behavior of $\mathrm{Mg}-\mathrm{Mn}-\mathrm{Zn}$ alloy for bone implant application. J Biomed Mater Res A 2007; 83(3): 703-711.

13. Staiger MP, Pietak AM, Huadmai J, et al. Magnesium and its alloys as orthopedic biomaterials: a review. Biomaterials 2006; 27(9): 1728-1734.

14. Witte F, Reifenrath J, Müller PP, et al. Cartilage repair on magnesium scaffolds used as a subchondral bone replacement. Materialwissenschaft und Werkstofftechnik 2006; 37(6): 504-508.

15. Zartner P, Cesnjevar R, Singer H, et al. First successful implantation of a biodegradable metal stent into the left pulmonary artery of a preterm baby. Catheter Cardiovasc Interven 2005; 66(4): 590-594.

16. Huehnerschulte TA, Angrisani N, Rittershaus D, et al. In vivo corrosion of two novel magnesium alloys ZEK 100 and AX30 and their mechanical suitability as biodegradable implants. Materials 2011; 4: 1144-1167.

17. Beck A. Magnesium und seine Legierungen. 2. Auflage edition. Springer, 2001.

18. Shaw BA. Corrosion resistance of magnesium alloys. ASM handbook, Vol 13A Corrosion: fundamentals, testing and protection. Metals Park, Ohio: ASM, 2003, pp.692-696.

19. Song GL and Atrens A. Corrosion mechanisms of magnesium alloys. Adv Eng Mater 1999; 1(1): 11-33.

20. Witte $\mathrm{F}$, Kaese $\mathrm{V}$, Haferkamp $\mathrm{H}$, et al. In vivo corrosion of four magnesium alloys and the associated bone response. Biomaterials 2005; 26(17): 3557-3563.

21. Von Der Höh N, Bormann D, Lucas A, et al. Influence of different surface machining treatments of magnesiumbased resorbable implants on the degradation behavior in rabbits. Adv Eng Mater 2009; 11(5): B47-B54.

22. Thomann M, Krause C, Angrisani N, et al. Influence of a magnesium-fluoride coating of magnesium-based implants $(\mathrm{MgCa} 0.8)$ on degradation in a rabbit model. J Biomed Mater Res A 2010; 93(4): 1609-1619.

23. Pietak A, Mahoney P, Dias GJ, et al. Bone-like matrix formation on magnesium and magnesium alloys. $J$ Mater Sci Mater Med 2008; 19(1): 407-415.

24. Zreiqat H, Evans P and Howlett CR. Effect of surface chemical modification of bioceramic on phenotype of human bone-derived cells. J Biomed Mater Res 1999; 44(4): 389-396. 
25. Karageorgiou V and Kaplan D. Porosity of 3D biomaterial scaffolds and osteogenesis. Biomaterials 2005; 26(27): 5474-5491.

26. Kuboki Y, Takita H, Kobayashi D, et al. BMP-induced osteogenesis on the surface of hydroxyapatite with geometrically feasible and nonfeasible structures: topology of osteogenesis. J Biomed Mater Res 1998; 39(2): 190-199.

27. Zreiqat H, Howlett CR, Zannettino A, et al. Mechanisms of magnesium-stimulated adhesion of osteoblastic cells to commonly used orthopaedic implants. J Biomed Mater Res 2002; 62(2): 175-184.

28. Revell PA, Damien E, Zhang XS, et al. The effect of magnesium ions on bone bonding to hydroxyapatite coating on titanium alloy implants. Key Eng Mater 2004; 254-256: 447-450.

29. Yamasaki Y, Yoshida Y, Okazaki M, et al. Synthesis of functionally graded $\mathrm{MgCO}_{3}$ apatite accelerating osteoblast adhesion. J Biomed Mater Res 2002; 62(1): 99-105. 